\title{
Characterization of Noncovalent Protein- Ligand Complexes and Associated Enzyme Intermediates of GlcNAc-6-O-Sulfotransferase by Electrospray Ionization FT-ICR Mass Spectrometry
}

\author{
Yonghao Yu, Colleen E. Kirkup, Na Pi, and Julie A. Leary \\ Department of Chemistry, University of California at Berkeley, Berkeley, California, USA
}

\begin{abstract}
In this study, a GlcNAc-6-O-Sulfotransferase, NodST and its complexation with the substrate 3'-phosphoadenosine 5'-phosphosulfate (PAPS) and the inhibitor 3'-phosphoadenosine 5'phosphate (PAP) were studied using Fourier transform ion cyclotron resonance (FTICR) mass spectrometry. In addition, using isotopically labeled substrate, we have successfully confirmed a sulfated enzyme intermediate, which was predicted by the MS kinetic measurement. It is also shown that information regarding solution binding affinities can be obtained using electrospray ionization (ESI)-FTICR mass spectrometry. The relative binding constants, $\mathrm{K}_{\mathrm{d}}(\mathrm{PAPS})$ / $\mathrm{K}_{\mathrm{d}}(\mathrm{PAP})$, derived from the solution and gas phase were very similar, which suggests that the binding domain of this particular enzyme system, given known structures of other sulfotransferases, may be preserved during the transmission of the complex from solution to the gas phase. (J Am Soc Mass Spectrom 2004, 15, 1400-1407) (c) 2004 American Society for Mass Spectrometry
\end{abstract}

$\mathrm{O}$ ver the course of the past few years, it has become obvious that mass spectrometry can be used to study biological events to gain important information in the areas of protein folding [1], post-translational modification [2], and protein expression profiling [3]. One of the most rapidly expanding applications of ESI-MS is the study of protein-ligand noncovalent complexes [4-7]. Finely controlled instrument conditions such as capillary heating, accelerating voltages at the capillary exit, and the gas pressure at the nozzle-skimmer region are critical to the preservation of some noncovalent complexes in the gas phase [8]. In generating these complexes, proteins are mixed with their ligands in solution and the intact noncovalent complexes are observed in the gas phase for proteinsubstrate [9], protein-inhibitor [10], and intact multimeric proteins complexes [11]. Moreover, once these desolvated molecules are in the gas phase, molecular weight, binding stoichiometry, and relative/absolute binding strength can be determined using mass spectrometry [12-16]. Sulfotransferases, in particular, can be

Published online August 28, 2004

Address reprint requests to Dr. J. A. Leary, Department of Chemistry, University of California at Berkeley, 410 Latimer Hall, Berkeley, CA 94720, USA E-mail: leary@socrates.berkeley.edu investigated in significant detail and information concerning the mechanism of catalysis can be garnered.

Sulfated molecules exist in biological systems as sulfated small molecules, carbohydrates and proteins [17]. These molecules have been implicated in a variety of biological processes, particularly those involving cellular adhesion. For example, the entry of HIV-1 into the target cell is initiated by an interaction between the glycoprotein gp120 and CD4; this is followed by the binding of CCR 5 to gp120. It has been shown that only the CCR5, which is sulfated at the amino-terminal tyrosine residue, is the active co-receptor $[18,19]$. Posttranslationally sulfated glycoprotein GP $\mathrm{Ib} \alpha$ associates with GP $\mathrm{Ib} \beta$ and GP IX to form the GP Ib-IX complex [20]. This complex binds to the von Willebrand factor (vWf) and thus mediates the attachment of the platelets to the blood vessel wall in thrombosis. The binding capacity of the GP Ib-IX complex to the vWf is substantially decreased without the sulfated tyrosine residues on the GP Ib $\alpha$ subunit.

The sulfation of various molecules is catalyzed by a family of sulfotransferases that transfer the sulfuryl group from a universal donor substrate, $3^{\prime}$-phosphoadenosine $5^{\prime}$-phosphosulfate (PAPS), to the hydroxyl or amino group of small molecules. Rhizobium meliloti Nod factor sulfotransferase (NodST) belongs to the family of GlcNAc6ST carbohydrate sulfotransferases and specifi- 


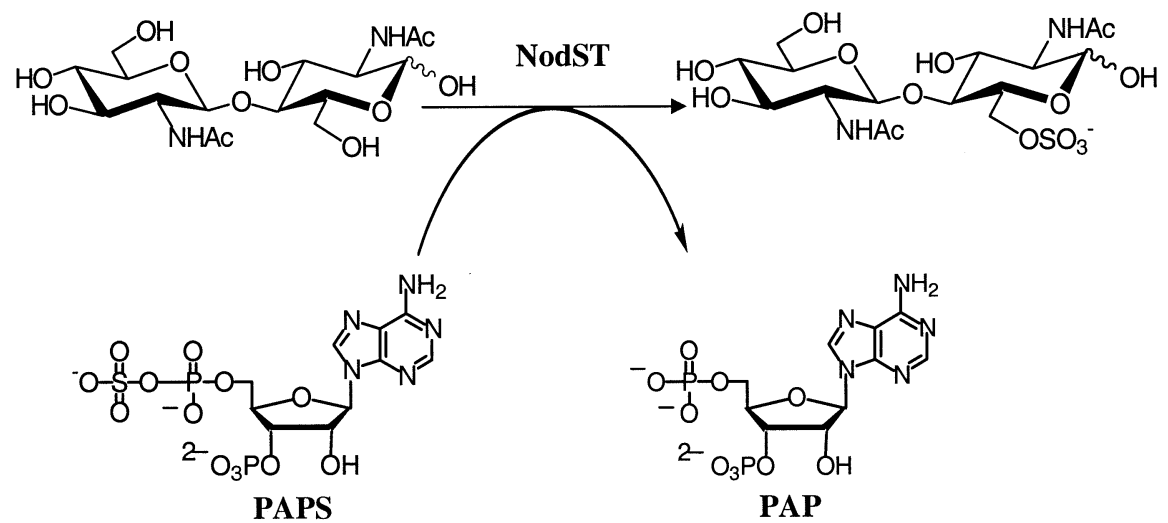

Scheme 1. The sulfuryl group transfer reaction catalyzed by NodST which yields the sulfated chitobiose and PAP.

cally sulfates the 6-hydroxyl group of the reducing terminal GlcNAc residue of a lipochitooligosaccharide using PAPS as the donor substrate. This transfer reaction results in the formation of the sulfated Nod factor, which is involved in root nodulation and bacterial infection [21]. In a similar manner, NodST can utilize chitobiose as the acceptor substrate to produce sulfated chitobiose (Scheme 1). Previous studies have shown that the substrate, PAPS, and the product inhibitor, 3'-phosphoadenosine 5'-phosphate (PAP), bind to NodST with the binding constants of $6.7 \mu \mathrm{M}$ and 1.8 $\mu \mathrm{M}$, respectively [22, 23]. Additionally, mass spectrometry was used to show that NodST catalyzes the sulfation using a random hybrid ping-pong Bi-Bi mechanism, supporting the formation of a sulfated-NodST intermediate [23].

In this study, FT-ICR mass spectrometry was used to investigate several important characteristics of NodST and its complexation with the substrates, PAPS and chitobiose, and the inhibitor, PAP. In so doing, we have successfully identified a sulfated enzyme intermediate, which was predicted by our previous study of NodST catalytic mechanism using an ESI-MS kinetic assay [23]. It is also shown that information regarding solution binding affinities can be obtained in the gas phase using ESI-FTICR mass spectrometry. Current data in combination with the information obtained from our previous kinetic studies $[22,23]$ suggests that the binding domain of this particular enzyme system is preserved during the transmission of the complex from solution to the gas phase. However, we have no definitive data suggesting that the entire protein conformation is preserved; only the binding domain.

\section{Experimental}

\section{General Materials and Methods}

Commassie plus protein assay reagent $(950 \mathrm{ml})$ and albumin standard $(10 \times 1 \mathrm{ml})$ were purchased from Pierce (Rockford, IL). Sulfotransferase, Nod Factor
(NodST) and 3'-phosphoadenosine 5'-phosphosulfate (PAPS) were purchased from Calbiochem (La Jolla, CA). Sequencing grade modified trypsin was purchased from Promega (Madison, WI), and 3'-phosphoadenosine 5'-phosphate (PAP), ATP sulfurylase from baker's yeast and inorganic pyrophosphatase from E. coli were purchased from Sigma Co. (St. Louis, $\mathrm{MO}$ ). Adenosine $5^{\prime}$-phosphosulfate (APS) kinase from E. coli was a gift from Professor Carolyn Bertozzi. $\left[{ }^{34} \mathrm{~S}_{\mathrm{Na}_{2}} \mathrm{SO}_{4}\right.$ was purchased from Icon Isotopes (Summit, NJ). HiTrap Q HP columns were purchased from Amersham (Piscataway, NJ). All the remaining chemicals were purchased from Sigma (St. Louis, MO) and used without further purification.

Since PAPS is easily hydrolyzed to PAP, the exact concentration of PAPS was determined by mass spectrometry on a Finnigan LCQ ion trap mass spectrometer (San Jose, CA). PAPS was dissolved in 80:20 methanol: ammonia acetate $(10 \mathrm{mM})$ solution and sprayed into the mass spectrometer to determine the ion intensity ratio of PAPS/PAP. Four micromolar PAP was then added and the ratio was again measured. The molar ratio of PAPS to PAP in the stock solution was thus calculated to be $85: 15$.

\section{FT-ICR Mass Spectrometry and Generation of Noncovalent Complexes}

Mass spectra were obtained on a Bruker 7-tesla FT-ICR MS equipped with an Analytica electrospray source (Bradford, CT). Solutions were infused at a rate of 1 $\mu \mathrm{l} / \mathrm{min}$. The nebulizing and drying nitrogen pressures were maintained at 50 and $30 \mathrm{psi}$, respectively. The bias on the glass capillary was kept at $\sim 4500 \mathrm{~V}$ and a $102{ }^{\circ} \mathrm{C}$ drying gas was used to assist the desolvation process. Further desolvation was achieved by collisions of the ions with neutral buffer gas at the nozzle-skimmer region using a $\sim 150 \mathrm{~V}$ capillary exit accelerating voltage. A throttle valve was installed to adjust the pressure at the nozzle-skimmer region to $\sim 1 \times 10^{-5}$ mbar. Ions 
were externally accumulated in a radio frequency-only hexapole for 1-2 s and two to eight ion packages were transferred into the ICR cell for mass analysis. All samples were collected using gated trapping. Excessive kinetic energy was removed by colliding the ions with Ar pulsed into the cell to a pressure of $\sim 10^{-7}$ mbar. A series of pump downs were applied to lower the pressure in the cell to $\sim 10^{-10}$ mbar and the trapping voltage was decreased to $\sim 0.5 \mathrm{~V}$. Ions were detected using chirp excitation and broad band data acquisition using an average of 16-160 time domain transients containing either $8 \mathrm{k}$ or $1024 \mathrm{k}$ data point. The original time domain free induction decay (FID) spectra were zero filled, Gaussian-multiplied and Fourier transformed. All the data were acquired and processed using Bruker Xmass version 6.0.0 software (Billerica, MA).

Solutions of $42.5 \mu \mathrm{M}$ of PAPS, $7.5 \mu \mathrm{M}$ of PAP, and 10 $\mu \mathrm{M}$ of NodST were mixed in a $60 \mathrm{mM}$ ammonia acetate solution $(\mathrm{pH}=7.5)$ previously incubated on ice and then infused into the ESI-FTICR mass spectrometer using positive ion mode detection. The spray chamber was wrapped with ice bags to prevent the protein sample from precipitating out from the buffer solution and the pressure in the nozzle-skimmer region was adjusted to $\sim 1 \times 10^{-5}$ mbar using the throttle valve. Finely controlled pressure in the nozzle-skimmer region by the throttle valve resulted in the ions being dragged through a viscous gas without being accelerated to high kinetic energy. The weakly associated noncovalent complexes ions were gently dried through a series of low energy collisions with the buffer gas without dissociation. The parameters of the ESI source, ion optics and cell were tuned for the best signal to noise ratio.

\section{Synthesis of the $\left[{ }^{34}\right.$ S]PAPS and Isotopic Labeling Experiments}

PAPS was synthesized enzymatically using ATP sulfurylase coupled with APS kinase as described by Burkart et al. [24]. Since the sulfation of the ATP has a small equilibrium constant, inorganic pyrophosphatase was also added in the reaction to hydrolyze the pyrophosphate and thus drive the first step of the enzymatic reaction. The second step includes phosphorylation of APS by ATP, which yields PAPS and ADP. A $1000 \mu \mathrm{l}$ solution containing $50 \mathrm{mM}$ Tris $(\mathrm{pH}=8.0), 30 \mathrm{mM} \mathrm{KCl}$, $40 \mathrm{mM} \mathrm{MgCl}_{2}, 1 \mathrm{mM}$ EDTA, $1 \mathrm{mM}$ DTT, $4 \mathrm{mM}$ ATP, 4

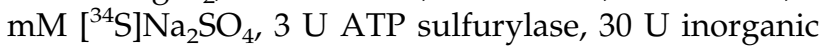
pyrophosphatase, and $14 \mathrm{mU}$ APS kinase was incubated under room temperature for $4 \mathrm{~h}$. The reaction solution was then loaded on a HiTrap Q HP anionexchange column and chromatographed by using a BioLogic LP system (Biorad, Hercules, CA). A solvent system consisting of Solvent $\mathrm{A}\left(50 \mathrm{mM} \mathrm{NH}_{4} \mathrm{OAc} \mathrm{pH}=\right.$ 6.8) and Solvent B ( $\left.2 \mathrm{M} \mathrm{NH}_{4} \mathrm{OAc} \mathrm{pH}=6.8\right)$ was used for elution at a flow rate of $1 \mathrm{ml} / \mathrm{min}$. The eluants were monitored by UV at $254 \mathrm{~nm}$. A typical elution contained a $30 \mathrm{ml}$ wash by Solvent A, followed by a $30 \mathrm{ml}$ linear gradient of 0 to $100 \%$ B in A and a $10 \mathrm{ml}$ wash for each of the Solvents A and B. Fractions that contained PAPS were identified by FTICR mass spectrometry and were subsequently pooled and lyophilized.

Trypsin digestion of both NodST and the NodSTPAPS (both ${ }^{32} S$ and ${ }^{34} S$ labeled PAPS) complex was performed. NodST was incubated with PAPS on ice for $0.5 \mathrm{~h}$. The enzyme was then denatured at room temperature and digested with trypsin $0.4 \%(\mathrm{w} / \mathrm{w})$ for $3 \mathrm{~h}$. A $100 \mu \mathrm{l}$ aliquot was then analyzed by FTICR mass spectrometry using negative ion detection without further desalting or separation. Masslynx 3.3 Build 004 (Manchester, UK) software was used to generate the theoretical tryptic digestion pattern of NodST.

\section{Results and Discussion}

\section{Noncovalent Complexation}

The ESI mass spectra of NodST are shown in Figure 1. Figure 1a represents the NodST sprayed from a solution of acetonitrile:water (80:20) with $1 \%$ formic acid, which indicates a large charge state distribution. When NodST was sprayed from $\mathrm{NH}_{4} \mathrm{OAc}$ at a $\mathrm{pH}$ value at 7.5 (Figure $1 b)$, only three charge states $(11+, 12+$, and $13+)$ were observed. Figure $1 \mathrm{c}$ is the resulting mass spectrum when the enzyme is sprayed from buffer with its substrate (PAPS) and inhibitor (PAP). Neither the noncovalent enzyme-substrate nor enzyme-inhibitor complex was observed when the sample was sprayed from organic solvent.

It has been suggested that proteins are denatured and readily extended in organic solvent [8].Thus, the high solvent accessibility of the basic sites in the unfolded structure gives rise to a large charge state distribution during the electrospray process. However, under physiological solution conditions, proteins are folded and the internal residues are not exposed to the solvent, which theoretically results in only surface basic sites becoming protonated when ions are transferred from the solution phase into the gas phase. It is of interest as to whether or not proteins take on different conformations in the gas phase when sprayed from these two different solution conditions. When proteins are unfolded in solution, it is very unlikely that the highly elongated structure will re-fold in the gas phase because of the Coulombic repulsion between the charged sites on the highly charged ions [8]. The extent of unfolding under physiological solution conditions when proteins are transferred into the gas phase is not clear, but it is highly possible that at least some of the originally folded structural features will be retained [25]. In the example shown herein, NodST sprayed from acidified organic solvent showed a dramatically different spectrum from that which was acquired using $\mathrm{NH}_{4} \mathrm{OAc}$ solution [26]. This may suggest that NodST is folded in buffer and that the binding domain may well be retained when passing into the gas phase [23]. Supporting evidence for this is provided below. 


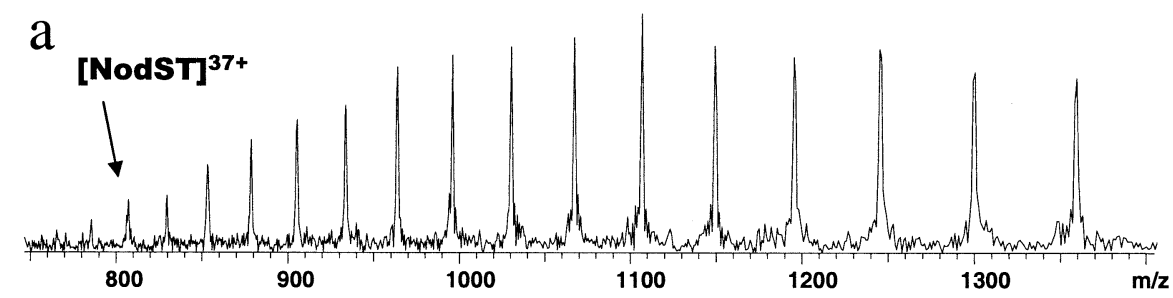

b

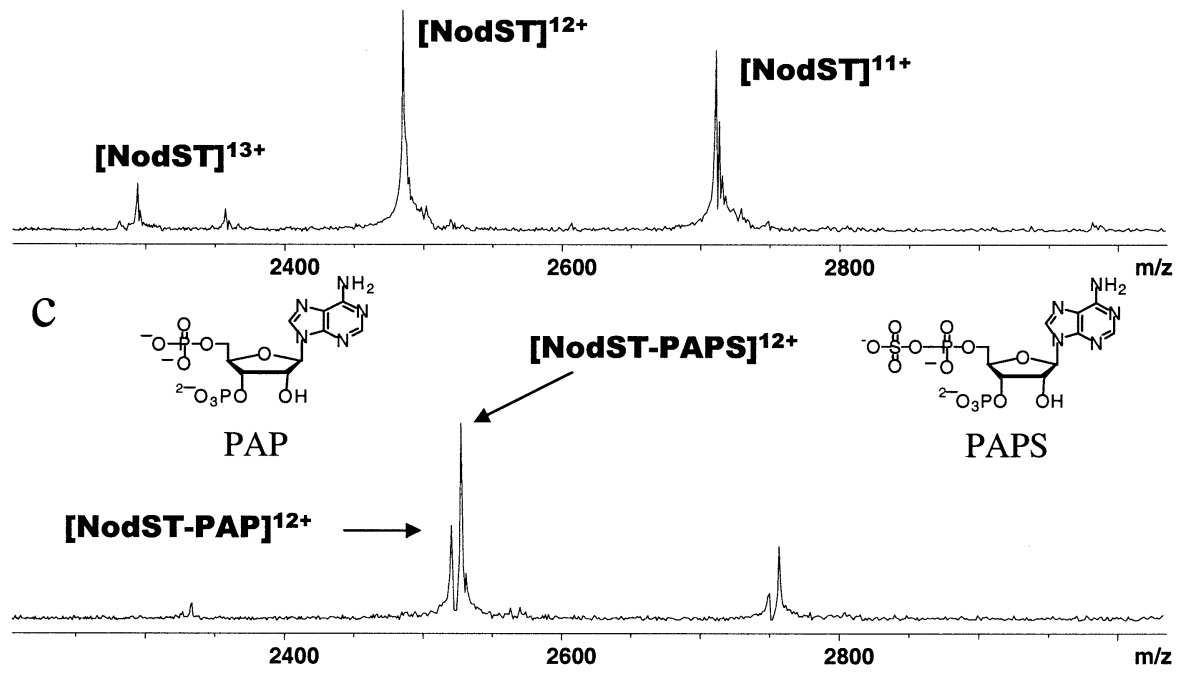

Figure 1. ESI mass spectra of $10 \mu \mathrm{M}$ NodST (a) acetonitrile: $\mathrm{H}_{2} \mathrm{O}$ (80:20) with $1 \%$ formic acid, (b) 60 $\mathrm{mM} \mathrm{NH}{ }_{4} \mathrm{OAc}, \mathrm{pH}=7.5$, and (c) $60 \mathrm{mM} \mathrm{NH}_{4} \mathrm{OAc}, \mathrm{pH}=7.5$ with $42.5 \mu \mathrm{M}$ PAPS and $7.5 \mu \mathrm{M}$ PAP.

Proteins may interact nonspecifically with other molecules in the ESI process and form random aggregates in the gas phase [6]. However, no dimer or higher multimeric states were observed in the ESI-FTICR mass spectra of $10 \mu \mathrm{M}$ NodST. This is in accordance with the previous gel filtration study in which NodST was found to exist as a monomer in solution [21]. When $10 \mu \mathrm{M}$ of NodST was incubated with $42.5 \mu \mathrm{M}$ PAPS and $7.5 \mu \mathrm{M}$ PAP, two new series of ions were observed (Figure 1c). The mass differences between these two new ions and NodST were calculated to be $507 \mathrm{Da}$ and $427 \mathrm{Da}$, which correspond to the noncolvalent adduction of PAPS and PAP, respectively. The five-fold excess of ligands was mixed with the protein so that both the binding and its specificity can be assessed [27]. Only one molecule each of the substrate (PAPS) and the inhibitor (PAP) was observed to be bound to the protein, even under the conditions of molar excess of the ligands. This allows for the direct determination of a 1:1 binding stoichiometry between NodST and PAPS or PAP. This observation also supports the possibility that specific proteinligand interactions remain intact during the ESI process. Interestingly, although the effective charge on PAPS and PAP is -4 in solution at the physiological $\mathrm{pH}$ value [28], there was no charge redistribution for NodST upon binding to these negatively charged ligands. Previous studies by Gao et al. [25] showed that using capillary electrophoresis, the protein-ligand binding stoichiometry can be determined by calculating the charge de- crease of carbonic anhydrase upon ligand binding. The lack of such change in the mass spectrometry experiments suggests that PAPS and PAP may bind to NodST as the neutral forms. If this were not the case, one would expect to have seen a redistribution of the NodST charge states upon complexation to the ligands.

\section{Measurement and Comparison of the Relative Dissociation Constants}

It is reasonable to assume that the ionization efficiency of the different NodST-ligand noncovalent complexes is similar because the major portion of the complex is comprised of the larger enzyme compound.

$$
\begin{aligned}
\frac{\mathrm{K}_{\mathrm{d}}(\mathrm{PAPS})}{\mathrm{K}_{\mathrm{d}}(\mathrm{PAP})} & =\frac{[\text { NodST-PAP }][\text { NodST }][\text { PAPS }]}{[\text { NodST-PAPS }][\text { NodST }][\text { PAP }]} \\
& =\frac{[\text { NodST-PAP }][\text { PAPS }]}{[\text { NodST-PAPS }][\text { PAP }]}
\end{aligned}
$$

Thus it was possible to determine the concentrations of [NodST-PAPS], [NodST-PAP], [PAPS] and [PAP] using the abundance of the $12+$ charge state of [NodSTPAPS], and [NodST-PAP] ions and by knowing the starting concentrations of enzyme and ligands. The ratio of the different NodST complexes can then be used to calculate the relative dissociation constants using eq 1. 


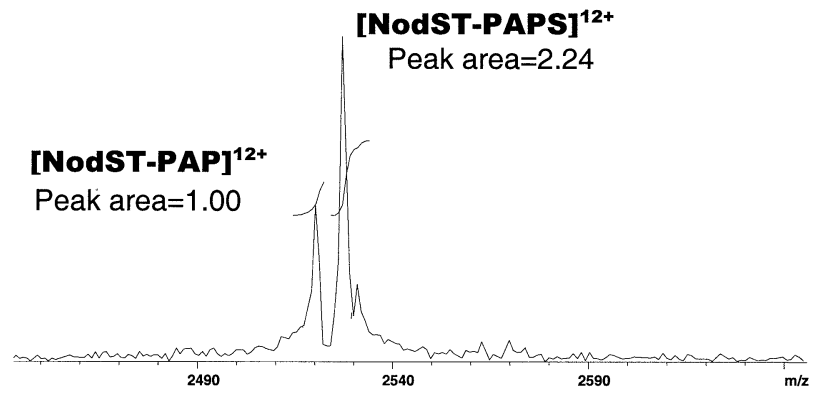

Figure 2. Peak area calculations of $[\text { NodST-PAPS }]^{12+}$ and [NodST-PAP] $^{12+}$ ions.

The solution concentrations of the noncovalent complexes can be correlated to the MS data if we assume the ligands have no effect on the ionization efficiency of the entire protein-ligand noncovalent complex. The peak areas of [NodST-PAPS] ${ }^{12+}$ and [NodST-PAP] ${ }^{12+}$ charge states were determined to be 2.24 and 1.00 using numeric integration (Figure 2). Using an initial concentration of $10 \mu \mathrm{M}$ for NodST $\left([\mathrm{E}]_{0}\right)$, concentrations of the NodST-PAPS and NodST-PAP complexes were determined to be $6.9 \mu \mathrm{M}$ and $3.1 \mu \mathrm{M}$ based on their relative ion intensity. The concentrations of free PAPS and PAP were calculated to be $35.6 \mu \mathrm{M}$ and $4.4 \mu \mathrm{M}$, using the initial concentrations of $42.5 \mu \mathrm{M}$ and $7.5 \mu \mathrm{M}$, respectively. This was achieved by subtracting the [NodSTPAPS] from the initial [PAPS]. The [PAP] was calculated in the same manner. Since no $\left[\right.$ NodST] ${ }^{12+}$ was observed, the concentration of free NodST was assumed to be $0 \mu \mathrm{M}$ (Figure 2). A similar result was obtained when the $11+, 12+$, and $13+$ were combined to calculate this ratio. Therefore, the ratio of $K_{d}(P A P S) /$ $\mathrm{K}_{\mathrm{d}}(\mathrm{PAP})$ (eq 1) was determined to be $3.7 \pm 0.2$ based on the gas phase data. This value was obtained from three replicate experiments.

The $\mathrm{K}_{M}$ (PAPS) and $\mathrm{K}_{\mathrm{i}}$ (PAP) were previously determined to be $6.7 \mu \mathrm{M}$ and $1.8 \mu \mathrm{M}$ from the solution kinetics [22]. Since we know that the NodST-ligand noncovalent complexes are in rapid equilibrium with the free enzyme and the ligands in solution, then $\mathrm{K}_{\mathrm{d}}(\mathrm{PAPS}) / \mathrm{K}_{\mathrm{d}}(\mathrm{PAP})$ is equal to $\mathrm{K}_{\mathrm{M}} / \mathrm{K}_{\mathrm{i}}$, the latter of which is then calculated to be $3.7 \pm 0.3$ (triplicate measurements). This result is very intriguing and clearly suggests that, for this particular example, the binding domain is preserved from solution to the gas phase.

Key questions in using mass spectrometry to study noncovalent complexes include whether the complexes are dissociating during the transfer from solution into the gas phase and to what extent solution interactions are preserved in the gas phase. For example, high voltages on the nozzle-skimmer region have been shown to influence collisions between ions and buffer gas molecules, and dissociation of the noncovalent complexes occurs $[6,8]$. Previous studies of noncovalent complexes using mass spectrometry suggest that ionic interaction or hydrogen-bonding may correlate with the ESI or MS/MS stability [8]. However, there is little or no correlation between solution and gas phase binding when hydrophobic interactions dominate [29]. It is also possible that during ESI, ligands present in excess concentrations may associate with the protein nonspecifically. In the case of NodST, the relative binding constants from gas phase data were measured and compared with solution binding constants determined from solution kinetics in order to address the possibility of non-specific association. The excellent agreement between the gas and solution phase data supports the hypothesis that the NodST noncovalent complexes remained undisturbed in the ESI process.

\section{Isotopic Labeling and Detection of a Sulfated NodST Intermediate}

Mass spectrometry has been shown to be quite useful in the identification of covalent enzyme intermediates as observed by Wicki and coworkers who detected a covalent B-glycosidase intermediate by using mass spectrometry [30]. After first labeling the active site of the nucleophile with a fluorinated substrate, they used pepsin digestion to identify a glycosylated peptide by MS/MS. Using a somewhat different approach, we have been able to show the existence of a covalent sulfated intermediate of NodST by first determining the mechanism of catalysis via kinetic parameters [23]. According to our previous study, NodST catalyzes the sulfation reaction via a random hybrid ping-pong mechanism in which the sulfuryl group of PAPS is first transferred to the enzyme via a covalent bond. It is this sulfated intermediate which subsequently transfers the sulfuryl group to the second substrate, chitobiose. If our determination of a ping-pong mechanism is correct, then the described sulfated intermediate should be detectable by mass spectrometry. In order to prove this theory we first digested NodST with trypsin and mapped the resulting peptide fragments. This experiment was then repeated after incubating the enzyme with PAPS. Upon trypsin digestion of the NodST-PAPS complex, one particular peptide, $\mathrm{T}_{2-3}$, shifted by $80 \mathrm{Da}$. The $T_{2-3}$ peptide corresponds to the amino acid sequence, 19-TGTHYLEELVNEHPNVLSNGELLNTYDTNWPDKER-53 and appears at 80 Da higher in mass for the NodST-PAPS digest [23].

In order to rule out the presence of a phosphorylated intermediate whose nominal mass is isobaric with the sulfated analog, $\left[{ }^{34}\right.$ S]PAPS was synthesized and used as an isotope label. After incubating NodST with the $\left[{ }^{34} \mathrm{~S}\right] \mathrm{PAPS}$, the labeled complex was again digested with trypsin. Figure 3 compares the sulfated $\mathrm{T}_{2-3}$ tryptic peptide when NodST was labeled using $\left[{ }^{34} \mathrm{~S}\right] \mathrm{PAPS}$ and $\left.{ }^{32} \mathrm{~S}\right] \mathrm{PAPS}$. The monoisotopic peak of the tryptic $\left[\mathrm{T}_{2-3^{-}}\right.$ $\left.\mathrm{SO}_{3} \mathrm{H}\right]^{3-}$ peptide shifted by 2.000 Da when NodST was incubated with $\left[{ }^{34} \mathrm{~S}\right] \mathrm{PAPS}$ (Figure 3a) compared with $\left[{ }^{32}\right.$ S]PAPS (Figure 3b). This is in excellent agreement 


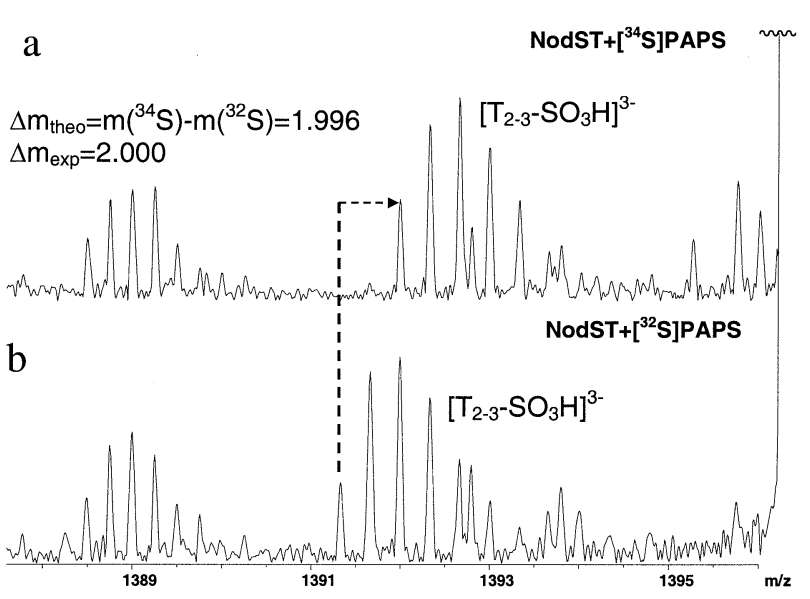

Figure 3. ESI-FTICR MS spectra of $\left[\mathrm{T}_{2-3}-\mathrm{SO}_{3} \mathrm{H}\right]^{3-}$ when NodST was incubated with (a) $\left.{ }^{34} \mathrm{~S}\right] \mathrm{PAPS}$ and $(\mathbf{b})\left[{ }^{32} \mathrm{~S}\right] \mathrm{PAPS}$ followed by trypsin digestion.

with the theoretical mass difference of 1.996 Da between the ${ }^{34} \mathrm{~S}$ and ${ }^{32} \mathrm{~S}$. The observed mass shift of the sulfated $\mathrm{T}_{2-3}$ peptide using stable isotope labeled sulfur rules out the possibility that this ion arises from the isobaric phosphorylated peptide.

The product inhibition patterns obtained using the ESI-MS assay were consistent with the two site hybrid ping-pong mechanism [23]. In this mechanism, the two substrates bind independently and randomly at two different sites on NodST. A flexible domain between the two binding sites becomes sulfated by PAPS, bound in one site, producing the covalent sulfated NodST intermediate. This is followed by the transfer of the sulfuryl group to the acceptor substrate, chitobiose, bound at the second site.

The results shown herein, together with the previously measured kinetic constant calculations and mechanism studies [23] indicate that PAP and PAPS occupy one binding site, while chitobiose and sulfated chitobiose occupy a different site on the protein such that a sulfated intermediate is produced before transfer of the sulfuryl group to the second substrate. Unfortunately, there has been no report on the crystal structure for this protein and thus we do not know its conformation or folding properties. However, based on our data it would appear that folding of the protein must take place in order to bring the second substrate into close enough proximity with the sulfate group on the first binding site. If this is the case, and if the binding domain is retained during transfer from the solution to the gas phase, one should be able to measure product formation over time in the gas phase.

Figure 4 shows the negative mode mass spectrum taken at different time periods during the NodST reaction. A syringe was filled with enzyme, PAPS and chitobiose and immediately introduced into the ESI source at a rate of $1 \mu \mathrm{l} / \mathrm{min}$. As can be seen, the amount of sulfated chitobiose produced increases over the timescale of the reaction as does the resulting PAP product. This clearly indicates that product is forming over time and again supports the hypothesis that the correct binding site conformation of the enzyme and its ligands

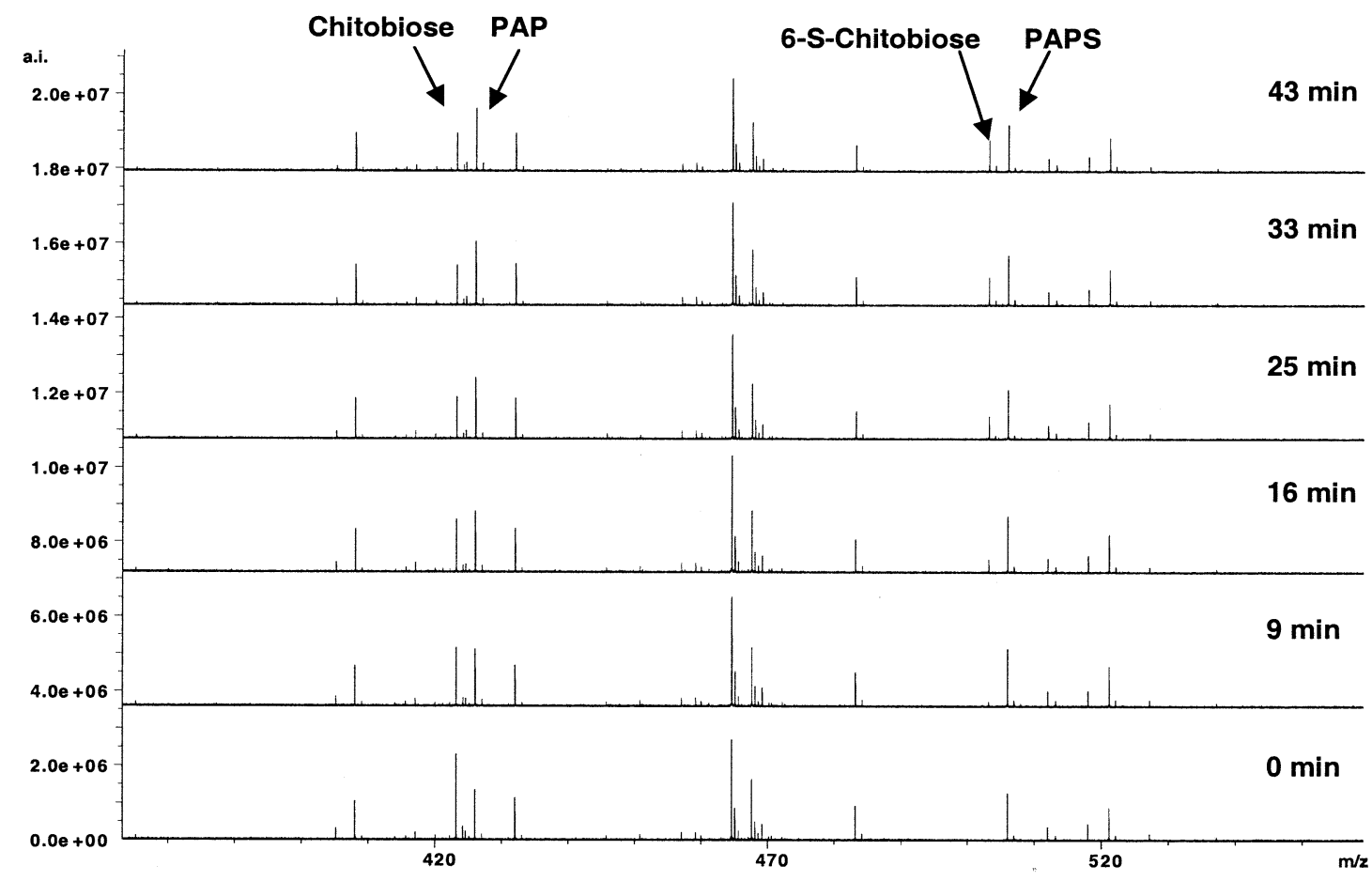

Figure 4. Real-time monitoring of the formation of the sulfated chitobiose when NodST was incubated with both of the substrates, PAPS and chitobiose. 
generated in solution is effectively transferred into the gas phase. This data could not be obtained when the enzyme and ligands were sprayed from organic solution, thus indicating that this is not an artifact of gas phase ion chemistry.

\section{Conclusion}

Protein ligand noncovalent complexes have been studied by ESI-FTICR mass spectrometry using the NodST enzyme system. Enzyme-substrate and enzyme-inhibitor noncovalent complexes have been generated and their kinetics and binding properties studied using both solution and gas phase methods. Stable isotope labeling was used to unambiguously identify a covalent sulfated intermediate of the catalytic reaction and relative dissociation constants were measured. These constants suggest that the binding domain is preserved in transferring the complexes from solution into the gas phase. This was further supported by mass spectral studies showing the generation of the sulfated product over time.

\section{Acknowledgments}

The authors gratefully acknowledge funding for this research by a grant from the National Institute of Health, GM 63581.

\section{References}

1. Deng, Y.; Smith, D. L. Hydrogen Exchange Demonstrates Three Domains in Aldolase Unfold Sequentially. J. Mol. Biol. 1999, 294, 247-258.

2. Oda, Y.; Nagasu, T.; Chait, B. T. Enrichment Analysis of Phosphorylated Proteins as a Tool for Probing the Phosphoproteome. Nat. Biotechnol. 2001, 19, 379-382.

3. Gygi, S. P.; Rist, B.; Aebersold, R. Measuring Gene Expression by Quantitative Proteome Analysis. Curr. Opin. Biotechnol. 2000, 11, 396-401.

4. Aquilina, J. A.; Benesch, J. L. P.; Bateman, O. A.; Slingsby, C.; Robinson, C. V. Polydispersity of a Mammalian Chaperone: Mass Spectrometry Reveals the Population of Oligomers in aB-Crystallin. Proc. Natl. Acad. Sci. U.S.A. 2003, 100, 1061110616.

5. Loo, J. A. Electrospray Ionization Mass Spectrometry: A Technology for Studying Noncovalent Macromolecular Complexes. Int. J. Mass Spectrom. Ion Processes 2000, 200, 175-186.

6. Loo, J. A. Studying Noncovalent Protein Complexes by Electrospray Ionization Mass Spectrometry. Mass Spectrom. Rev. $1997,16,1-23$.

7. Sobott, F.; Robinson, C. V. Protein Complexes Gain Momentum. Curr. Opin. Struct. Biol. 2002, 12, 729-734.

8. Smith, R. D.; Bruce, J. E.; Wu, Q.; Lei, Q. P. New Mass Spectrometric Methods for the Study of Noncovalent Associations of Biopolymers. Chem. Soc. Rev. 1997, 26, 191-202.

9. Prinz, H.; Lavie, A.; Scheidig, A. J.; Spangenberg, O.; Konrad, M. Binding of Nucleotides to Guanylate Kinase, p21ras, and Nucleoside-Diphosphate Kinase Studied by Nano-Electrospray Mass Spectrometry. J. Biol. Chem. 1999, 274, 35337-35342.

10. Wu, Q.; Gao, J.; Joseph-McCarthy, D.; Sigal, G. B.; Bruce, J. E.; Whitesides, G. M.; Smith, R. D. Carbonic Anhydrase-Inhibitor Binding: From Solution to the Gas Phase. J. Am. Chem. Soc. 1997, 119, 1157-1158.
11. Light-Wahl, K. J.; Schwartz, B. L.; Smith, R. D. Observation of the Noncovalent Quaternary Associations of Proteins by Electrospray Ionization Mass Spectrometry. J. Am. Chem. Soc. 1994, 116, 5271-5278.

12. Loo, J. A.; Hu, P.; McConnell, P.; Mueller, W. T. A Study of Src SH2 Domain Protein-Phosphopeptide Binding Interactions by Electrospray Ionization Mass Spectrometry. J. Am. Soc. Mass Spectrom. 1997, 8, 234-243.

13. Zhu, M. M.; Rempel, D. L.; Gross, M. L. Modeling Data from Titration, Amide H/D Exchange, and Mass Spectrometry to Obtain Protein-Ligand Binding Constants. J. Am. Soc. Mass Spectrom. 2004, 15, 388-397.

14. Zhu, M. M.; Rempel, D. L.; Du, Z.; Gross, M. L. Quantification of Protein-Ligand Interactions by Mass Spectrometry, Titration, and H/D Exchange: PLIMSTEX. J. Am. Chem. Soc. 2003, 125, 5252-5253.

15. Powell, K. D.; Ghaemmaghami, S.; Wang, M. Z.; Liyuan, M.; Oas, T. G.; Fitzgerald, M. C. A General Mass SpectrometryBased Assay for the Quantitation of Protein-Ligand Binding Interactions in Solution. J. Am. Chem. Soc. 2002, 124, 1025610257.

16. Powell, K. D.; Fitzgerald, M. C. The Accuracy and Precision of a New H/D Exchange- and Mass Spectrometry-Based Technique for Measuring the Thermodynamic Properties of Protein-Peptide Complexes. Biochemistry 2003, 42, 4962-4970.

17. Grunwell, J. R.; Rath, V. L.; Rasmussen, J.; Cabrilo, Z.; Bertozzi, C. R. Characterization and Mutagenesis of Gal/GlcNAc6-O-Sulfotransferases. Biochemistry 2002, 41, 15590-15600.

18. Cormier, E. G.; Persuh, M.; Thompson, D. A. D.; Lin, S. W.; Sakmar, T. P.; Olson, W. C.; Dragic, T. Specific Interaction of CCR5 Amino-Terminal Domain Peptides Containing Sulfotyrosines with HIV-1 Envelope Glycoprotein gp120. Proc. Natl. Acad. Sci. U.S.A. 2000, 97, 5762-5767.

19. Seibert, C.; Cadene, M.; Sanfiz, A.; Chait, B. T.; Sakmar, T. P. Tyrosine Sulfation of CCR5 N-Terminal Peptide by Tyrosylprotein Sulfotransferases 1 and 2 Follows a Discrete Pattern and Temporal Sequence. Proc. Natl. Acad. Sci. U.S.A. 2002, 99, 11031-11036.

20. Dong, J.; Li, C. Q.; Lopez, J. A. Tyrosine Sulfation of the Glycoprotein Ib-IX Complex: Identification of Sulfated Residues and Effect on Ligand Binding. Biochemistry 1994, 33, 13946-13953.

21. Ehrhardt, D. W.; Atkinson, E. M.; Faull, K. F.; Freedberg, D. I.; Sutherlin, D. P.; Armstrong, R.; Long, S. R. In Vitro Sulfotransferase Activity of NodH, a Nodulation Protein of Rhizobium meliloti Required for Host-Specific Nodulation. J. Bacteriol. $1995,177,6237-6245$.

22. Pi, N.; Armstrong, J. I.; Bertozzi, C. R.; Leary, J. A. Kinetic Analysis of NodST Sulfotransferase Using an Electrospray Ionization Mass Spectrometry Assay. Biochemistry 2002, 41, 13283-13288

23. Pi, N.; Yu, Y.; Leary, J. A. Observation of a Hybrid Random Ping-Pong Mechanism of Catalysis for NodST: A Mass Spectrometry Approach. Protein Sci. 2004, 13, 903-912.

24. Burkart, M. D.; Izumi, M.; Chapman, E.; Lin, C.-H.; Wong, C.-H. Regeneration of PAPS for the Enzymatic Synthesis of Sulfated Oligosaccharides. J. Org. Chem. 2000, 65, 5565-5574.

25. Gao, J.; Wu, Q.; Carbeck, J.; Lei, Q. P.; Smith, R. D.; Whitesides, G. M. Probing the Energetics of Dissociation of Carbonic Anhydrase-Ligand Complexes in the Gas Phase. Biophys. J. 1999, 76, 3253-3260.

26. Loo, J. A.; Loo, R. R. O.; Udseth, H. R.; Edmonds, C. G.; Smith, R. D. Solvent-Induced Conformational Changes of Polypeptides Probed by Electrospray-Ionization Mass Spectrometry. Rapid Commun. Mass. Spectrom. 1991, 5, 101-105.

27. Cheng, X.; Harms, A. C.; Goudreau, P. N.; Terwilliger, T. C.; Smith, R. D. Direct Measurement of Oligonucleotide Binding 
Stoichiometry of Gene V Protein by Mass Spectrometry. Proc. Natl. Acad. Sci. U.S.A. 1996, 93, 7022-7027.

28. Negishi, M.; Pedersen, L. G.; Petrotchenko, E.; Shevtsov, S.; Gorokhov, A.; Kakuta, Y.; Pedersen, L. C. Structure and Function of Sulfotransferases. Arch. Biochem. Biophys. 2001, 390, 149-157.
29. Davidson, W.; Hopkins, J. L.; Jeanfavre, D. D.; Barney, K. L.; Kelly, T. A.; Grygon, C. A. Characterization of the Allosteric Inhibition of a Protein-Protein Interaction by Mass Spectrometry. J. Am. Soc. Mass Spectrom. 2003, 14, 8-13.

30. Wicki, J.; Rose, D. R.; Withers, S. G. Trapping Covalent Intermediates on $\beta$-Glycosidases. Methods Enzymol. 2002, 354, 84-105. 